\title{
Do Investors Trust or Simply Gamble?
}

\author{
Roman Sheremeta, Timothy Shields \\ The George L. Argyros School of Business and Economics \\ Chapman University \\ One University Drive \\ Orange, CA 92866
}

\begin{abstract}
We design an experiment to study individual behavior in a strategic information setting where the sender has economic incentives to deceive and the receiver has economic incentives to avoid deception. To ascertain whether subjects in the role of receiver glean information content from the sender's message, we elicit choices from risky gambles constructed to be mathematically equivalent to the information setting if the sender's message lacks information content. In the experiment subjects act simultaneously as a sender and receiver in a one-shot interaction. The findings of our experiment indicate that (i) subjects tend to act deceptively as senders but trusting as receivers, and (ii) as receivers, subjects glean information content from the senders' messages. Thus, we find investors (receivers) trust and investment cannot be rationalized solely by subjects' attitudes towards risk.
\end{abstract}

Key words: experiment, level- $k$ thinking, strategic communication, risk preference, beliefs

\section{Introduction}

"Oh, what a tangled web we weave when first we practice to believe." - Laurence J. Peter, misquoting Sir Walter Scott

In standard equilibria, predictions are constructed assuming that individuals entertain beliefs of others' strategies by analyzing what others might do and adopting rational strategies in response. In an information transmission setting with a conflict of interest between the sender and receiver, the sender's desire to misrepresent his or her information is anticipated in equilibrium by the receiver. Accordingly, the sender does not convey all information, but the receiver cannot be described as misled, as the receiver has unraveled the sender's intensions to misrepresent information.

Email addresses: sheremet@chapman.edu (Roman Sheremeta), shields@chapman.edu (Timothy Shields)

${ }^{1}$ We would like to thank Glenn Pfeiffer and Jack Stecher for their suggestions, our colleagues at the Argyros School of Business and Economics for their helpful comments, and Chapman University for its support.

Preprint submitted to elicit feedback
As the equilibrium theory of Crawford and Sobel (1982) predicts, when the preferences of the sender and receiver diverge, not all information is transmitted. However, while experimental senders do adopt deceptive transmission strategies, the senders transmit more information concerning the true state of nature than equilibria predict. Likewise, receivers rely more on the senders' messages than would be expected based on theoretical predictions (Sánchez-Pagés and Vorsatz, 2009; Kawagoe and Takizawa, 2008).

Research in the area of financial markets has provided empirical evidence that financial analysts exaggerate recommendations. Michaely and Womack (1999) attribute this documented bias to conflicts of interest between the analysts and investors, citing both brokerage commissions and the investment banking business as possible sources. Malmendier and Shanthikumar (2007) and Franco et al (2007) find evidence of differences in the reaction of investors, suggesting that some investors are misled by deceptive recommendations despite the disclosure of conflicts of interests.

In summary, both empirical and experimental evidence suggests that while senders tend to adopt deceptive prac-

November 6, 2010 
tices, receivers act on information sent as if they, in some sense, trust senders' messages. It is important, however, that any interpretation of behavior is a joint assumption upon the subjects' risk neutral preferences and beliefs of others strategies. In this work, we design an experiment to determine if receivers attempt to glean information content from senders' messages or are simply abiding by risk preferences. In the experiment subjects act simultaneously as a sender and receiver in a oneshot interaction of an information transmission game. We elicit choices from risky gambles constructed to be mathematically equivalent to the information setting if the sender's message lacks information content. The two main findings are that (i) subjects tend to act deceptively as senders but trusting as receivers, and (ii) as receivers, subjects glean information content from the senders messages.

\section{Theoretical Model and Experimental Design}

\subsection{The Model}

The experimental design is based on a sender-receiver information transmission game. The game proceeds as follows. In the first stage, the sender receives a private perfect signal $\theta \in\{A, B\}$ about the true state of nature. It is public knowledge that the state of the nature is equally likely to be favorable (i.e., $A$ ) or unfavorable (i.e., $B)$.

In the second stage, the sender releases a public message $\hat{\theta} \in\{A, B\}$ regarding the state, after receiving a private signal $\theta$. After receiving the message $\hat{\theta}$ the receiver can invest his cash endowment $\eta$, in which case he receives $\pi(\theta) \in\left\{\pi_{A}, \pi_{B}\right\}$. The investment pays $\pi_{B}<\eta$ when $\theta$ is $B$, and $\pi_{A}>\eta$ when $\theta$ is $A$. If the receiver decides not to invest he retains his endowment. The sender earns compensation $\lambda>0$ if the receiver decides to invest, or else receives nothing.

In the last stage, the true state of nature is revealed and both players receive their payoffs based on the state and depending on the investment decision of the receiver.

Utility functions are represented by $U($.$) where U^{\prime}()>$. 0 . As per rational exceptions prediction, a 'babbling equilibrium' should occur where the sender's report contains no information content. As such, the receiver anticipating deception will be skeptical of the message and invest only if inequality (1) is true:

$$
\frac{U\left(\pi_{A}\right)}{2}+\frac{U\left(\pi_{B}\right)}{2} \geq U(\eta)
$$

\subsection{Conditions and Parameters}

Holding $\pi_{B}$ and $\eta$ fixed, we manipulate $\pi_{A}$ over four conditions such that equation (1) is true in half of the conditions if the subject is risk neutral, i.e. $U^{\prime \prime}()=$.0 . This yields four elicited choices where we can ascertain whether equation (1) is true for each subject in each condition. Specifically, we set the receiver's endowment $\eta=10$, the unfavorable state-based payoff $\pi_{B}=0$, and the senders compensation $\lambda=13$ in all four conditions. We set the favorable state-based payoff $\pi_{A}$ to $12,18,22$, or 28 in four conditions, labeled condition 1 through 4 , respectively, shown in Table 1.

Table 1: Parameter Values for Conditions

\begin{tabular}{cccc} 
& Endowment & \multicolumn{2}{c}{ Investment Payoff } \\
& $\eta$ & $\pi_{B}$ & $\pi_{A}$ \\
\hline Condition 1 & 10 & 0 & 12 \\
Condition 2 & 10 & 0 & 18 \\
Condition 3 & 10 & 0 & 22 \\
Condition 4 & 10 & 0 & 28 \\
\hline \multicolumn{2}{c}{ All payoffs reported in US \$. }
\end{tabular}

\subsection{Attitudes towards risk}

The main assumption behind the standard equilibrium predictions is that subjects are risk-neutral. We elicit subjects' risk preferences from a set of four gambles as in Table 2. Assuming there is no information content in the sender's message, the gambles are equivalent to the four conditions of the sender-receiver game reported in Table 1. In each gamble, subjects are asked to state whether they prefer a safe option (equivalent to $\eta$ ) with probability one, or a risky option where the probability of the high value (equivalent to $\pi_{A}$ ) and the low value (equivalent to $\pi_{B}$ ) are both one-half. 
Table 2: Elicitation of Risk Preferences

\begin{tabular}{cccc} 
& Safe Option & \multicolumn{2}{c}{ Risky Option } \\
& & Low Value & High Value \\
\hline Gamble 1 & 10 & 0 & 12 \\
Gamble 2 & 10 & 0 & 18 \\
Gamble 3 & 10 & 0 & 22 \\
Gamble 4 & 10 & 0 & 28 \\
\hline
\end{tabular}

Risky option paid low or high values with equal probabilities.

All payoffs reported in US \$.

\subsection{Procedures}

The experiment was conducted at Chapman University at the Economic Science Institute. Subjects were recruited from a standard subject pool consisting primarily of undergraduate students. Subjects interacted with each other anonymously over a local computer network. The experiment was programmed and conducted using z-Tree (Fischbacher, 2007). The computers were placed within individual cubicles in such a way that all subjects could only view their own computer screen. The subjects acted both in the role of sender and receiver in four settings where we altered $\pi_{A}$. We elicited the subjects decisions using the strategy method for both roles and the four settings simultaneously.

Each of the three sessions lasted approximately fiftyfive minutes, consisted of 20 to 24 subjects, and were sequenced as follows:

1. An experimenter read the instructions aloud while each subject followed along with their own copy of the instructions. The instructions explained the experimental procedures, payoffs, and information structures used in the experiment (instruction available in the appendix). While going over the instructions, subjects were asked to write down their answers to several questions to ensure that they understood the instructions. Subjects' answers remained confidential to other subjects. The experimenter reviewed the correct answers privately with each subject. ${ }^{2}$ During and after the instructions were read, subjects were prompted to ask the experimenter in private any questions regarding the experiment procedures.

\footnotetext{
${ }^{2}$ Subjects on average answered less than one question incorrectly.
}

2. Each subject simultaneously played both roles of sender and receiver in all four settings, by choosing what message to send for each possible private signal and whether to invest for each possible sender's message. That is, for both values of the private signal, the sender made a binary choice to reveal the signal truthfully or not. For each possible message, the receiver made a binary choice either not to invest (labeled 'Stay') or to invest (labeled 'Go'). Consequently the subject was randomly and anonymously paired with other subjects. The computer randomly selected the setting, the role for payment and the state of nature, and presented an outcome screen to each individual subject. However, the outcome screen was not presented until the very end of the experiment, after all parts of the experiment were completed.

3. Then all subjects were asked to choose gambles in a task designed to elicit risk attitudes, using the method described in section 2.3. Subjects were not aware of this task until after we elicited their choices from the preceding step. One of the four choices was randomly selected for payment.

4. Each subject was paid a $\$ 7$ participation fee, the payoffs from one scenario and one gamble. Each participant individually signed and dated a payment receipt form and received payment. On average subjects earned $\$ 18$ in addition to their participation fee.

\section{Results}

\subsection{Descriptive Statistics}

We found no significant differences between the three sessions and thus report the combined results. For all hypothesis tests, we use the choices for each participant, yielding 64 independent observations. Unless stated otherwise we perform the Wilcoxon matchedpairs signed-rank test.

In the role of sender 13 of 64 subjects chose to always reveal their private information regarding the state. As shown in Figure 1, most subjects reveal the state A, but report $\mathrm{A}$ when the state is $\mathrm{B}$. The practice of deception is consistent across conditions; we find no significant differences in senders' behavior within subjects across conditions. 
Figure 1: Senders Choices Over Four Conditions

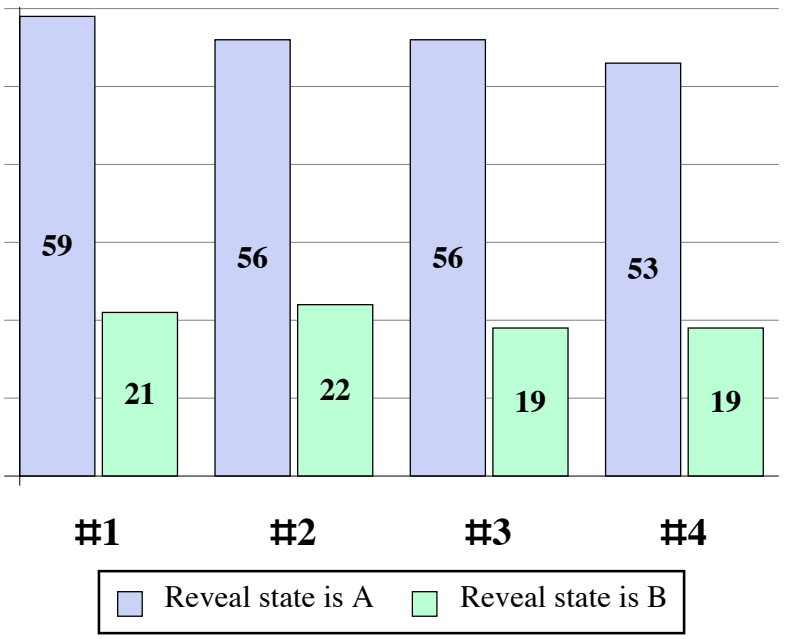

Number of 64 subjects reported.

In the role of receiver, 60 of 64 subjects chose to invest in at least one of the four conditions. The aggregate behavior is shown in Figure 2. Investment conditioned upon each message is increasing over conditions, from 42 out of 64 when $\pi_{A}=12$ to 58 out of 64 when $\pi_{A}=28$. The increase is significant a $p$-value $\leq 0.01$

Figure 2: Receivers Choices Over Four Conditions

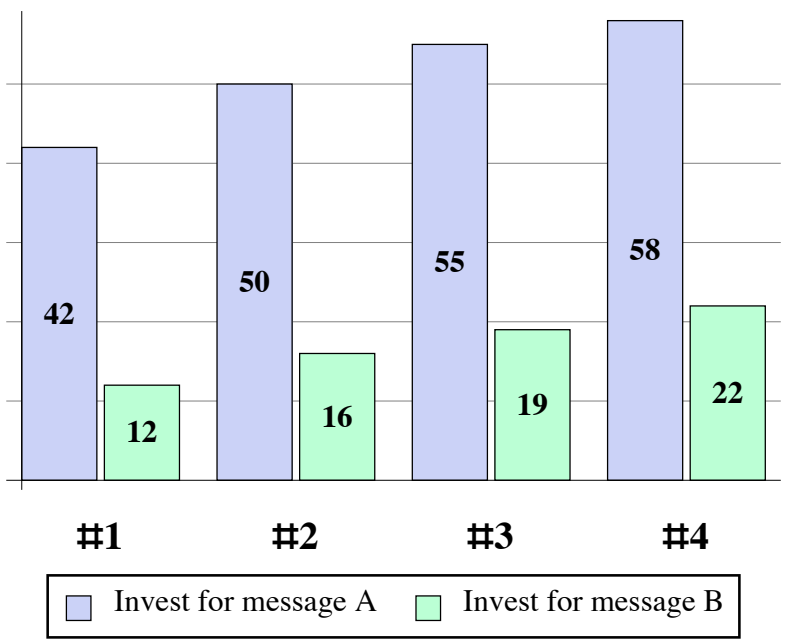

Number of 64 subjects reported.

\subsection{Analysis}

In order to ascertain whether subjects believe there is information content in other sender's report, we compare choices from the risk preference elicitation to the investment choices. If there is no perceived information content in the sender's report, the exercises are identical. These choices are shown in Figure 3. In all conditions we find that the number of subjects choosing to invest when the report is favorable exceeds those choosing the risky over safe gamble.

Figure 3: Receivers Investment and Risk Choices

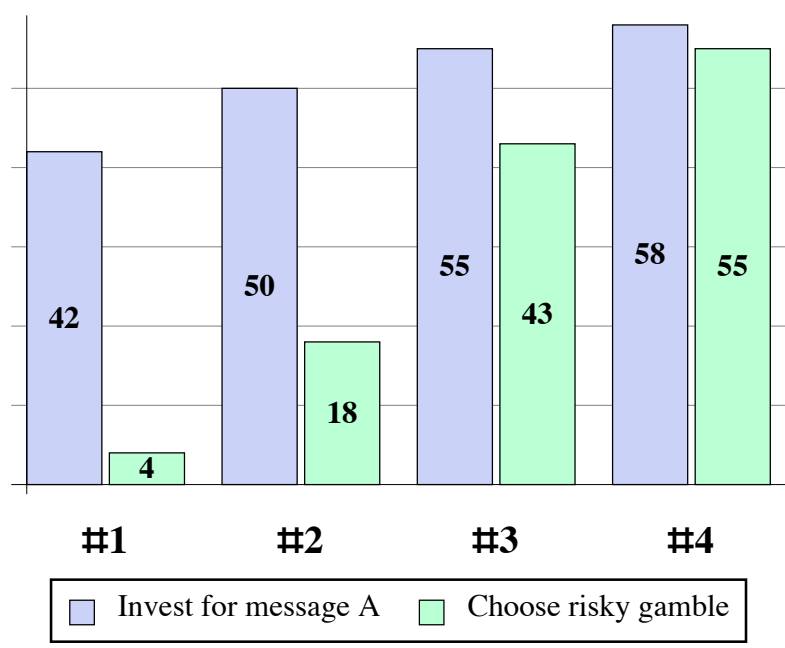

Number of 64 subjects reported who invest in four conditions and choose risky option in four gambles.

Comparing investment conditioned upon risk choices, there are 48 of 64 subjects who chose to invest despite choosing the safe option in the equivalent gamble, in at least one condition. Thus it appears that receivers are inferring information content from senders' messages. This interpretation is supported by statistical analysis comparing each subjects number of risky choices to the number of investment choices, yielding a $p$-value $\leq 0.01$.

To ascertain whether social norms of honesty and trusting drive behavior, we compare each subjects behavior across both roles. If the subject chose to always reveal their private information, the subject was coded as honest, else as deceptive. If they chose to invest when despite choosing the corresponding safe gamble, the subject was coded as trusting, otherwise skeptical. The re- 
sults are reported in Figure 4. Only one subject is classified as honest in the role of sender but skeptical in the role of receiver; this subject always chose the risky gamble. A majority of subjects are classified as deceptive and trusting. ${ }^{3}$ The null hypothesis that behavior is consistent (honest and trusting or deceptive and skeptical) is rejected, at a $p$-value $\leq 0.01$.

Figure 4: Subject Behavior Over Both Roles

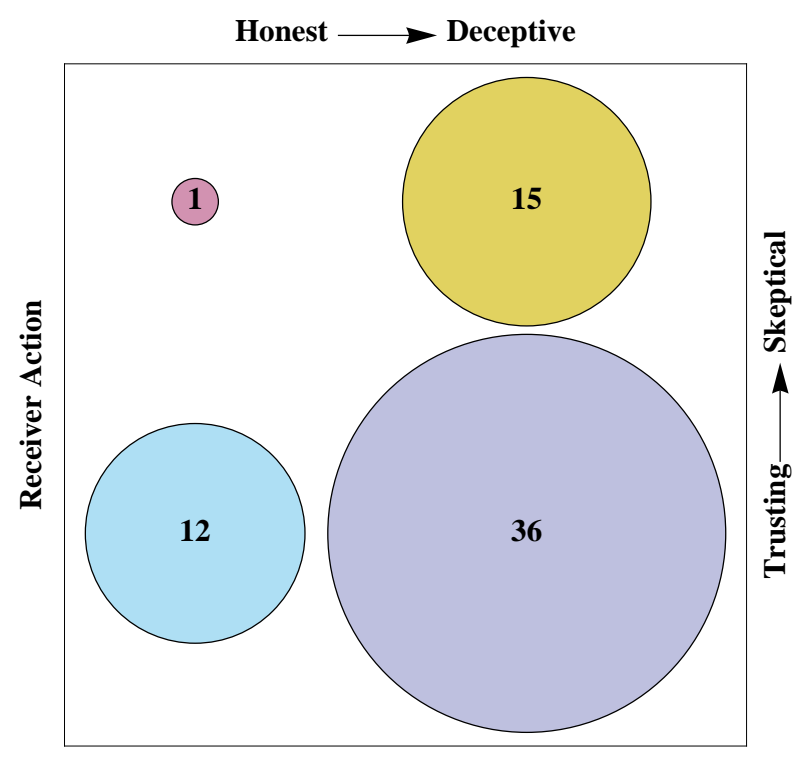

Sender Message

Number of subjects reported.

\subsection{Discussion}

What framework might predict why a subject in one role acts deceptively, but that same subject in another role trusts? Theories based on hierarchical thinking, commonly labeled level- $k$ thinking, posit that subjects behave strategically according to their beliefs of others' strategic behavior (Stahl and Wilson, 1994). Hierarchical thinking models define subjects by type, where each type represents the subject's belief of others' strategies. By first setting beliefs of a L-0 type, each successive type is modeled as playing the rational best response given that others are lesser types. By construction, L-1 best responds to L-0, L-2 best responds to a mixture of L-1 and L-0, and so forth.

\footnotetext{
${ }^{3}$ We do not claim behavior to be naïve, but if decision to invest is a best response to anticipated behavior, that behavior is not the subject's own behavior.
}

Crawford (2003) argues the base behavior in communication-game is to tell the truth as a sender and trust messages as a receiver. Consistent with hierarchical thinking models, we find that some subjects act honestly and trusting analogous to L-0. Half the subjects are deceptive and trusting analogous to $\mathrm{L}-1$, which is also the best response to others using L-0 strategies. Lastly, some subjects are deceptive and skeptical analogous to L-2, which is the best response to the majority of others using L-1 strategies. Only one of 64 subjects appears honest and skeptical. These findings are consistent with Blume et al (2001), Kawagoe and Takizawa (2008), and Wang et al (2010).

\section{Conclusion}

We designed an experiment to study individual behavior in a strategic information setting where the sender has economic incentives to deceive and the receiver has economic incentives to avoid deception. To ascertain whether subjects in the role of receiver gleaned information content from the sender's message, we elicited choices from risky gambles constructed to be mathematically equivalent to the information setting if the sender's message lacks information content. In the experiment subjects acted simultaneously as a sender and receiver in a one-shot interaction. We find that subjects tend to act deceptively as senders but trusting as receivers. However, as receivers, subjects glean information content from senders' messages. Finally, a majority of subjects in the role of receiver do not play a best response to their own behavior in the role of sender.

\section{References}

Blume, A DeJong, D; Kim, YG, Sprinkle, G (2001) Evolution of Communication with Partial Common Interest. Games and Economic Behavior, 37(1), pp. 79120.

Crawford V (2003) Lying for strategic advantage: Rational and boundedly rational mispresentation of intentions. The American Economic Review 93(1):133-149

Crawford V, Sobel J (1982) Strategic information transmission. Econometrica 50(6): 1431-1451

Fischbacher U (2007) z-tree: Zurich toolbox for ready-made economic experiments. Experimental Economics 10(2):171-178

Franco GD, Lu H, Vasvari FP (2007) Wealth transfer effects of analysts' misleading behavior. Journal of Accounting Research 45(1):71-110

Kawagoe T, Takizawa H (2008) Equilibrium refinement vs. level-k analysis: An experimental study of cheap-talk games with private information. Games and Economic Behavior 66(1):238-255 
Malmendier U, Shanthikumar DM (2007) Are small investors naive about incentives? Journal of Financial Economics 85(2):457-489

Michaely R, Womack KL (1999) Conflict of interest and the credibility of underwriter analyst recommendations. Review of Economic Studies 12(4):653-686

Sánchez-Pagés S, Vorsatz M (2009) Enjoy the silence: an experiment on truth-telling. Experimental Economics 12(2):220-241

Stahl D, Wilson PW (1994) Experimental evidence on players' models of other players. Journal of Economic Behavior \& Organization 25(3):309-327

Wang JTY, Spezio M, Camerer C (2010) Pinocchio's pupil: Using eyetracking and pupil dilation to understand truth telling and deception in sender-receiver games. The American Economic Review 100(3):984-1007

\section{A. Instructions}

This is a computerized experiment in the economics of decision-making. By following the instructions carefully and making good decisions, you may earn an additional amount of money besides the show up bonus of \$7. The currency used in this experiment is US dollars. The actual amount of additional money that you may earn will depend on your decisions and the decisions of other participants. Your money will be paid to you in cash after the experiment ends.

There are some rules you must follow:

1. Do not talk to others at any time during the experiment.

2. You will use your computer to select decisions during the experiment. Do not use your mouse or keyboard to play around with the software running on your computer. If you unintentionally or intentionally close the software program running on your computer, you will be asked to leave. If this happens, you will receive only your show up bonus.

3. If you have any questions during the experiment or instructions, please raise your hand. An experimenter will come to your location and answer your questions.

\section{Details of the Experiment}

\section{Grouping of Participants}

The experiment consists of a single round. Within this round you will be randomly paired with up to eight other participants, but into separate groupings. There are four settings. Within each setting there will be a single Sender and a single Receiver. You will make decisions both as a Sender and Receiver in all settings. These settings are separate, as your decisions in one setting or role will not affect what happens in the other settings.

You will never be told whom you are paired with. You are not allowed to communicate with others during the experiment.

\section{Overview of the Setting}

Each Receiver has one unit of the financial asset. At the end of each round, the computer determines the State of the economy, which in turn dictates the value of each Receivers asset. The chances of a particular State are:

Table A.1: Chances of States

$\begin{array}{lcc}\text { State } & \text { A } & \text { B } \\ \text { Chance of State } & 1 / 2 & 1 / 2\end{array}$

The State will be either A or B. There is an equal chance that the computer will select A or B. So, on average the computer will select A 50 percent of the time and B 50 percent of the time.

At the beginning of each round the Sender privately learns the State. No one else learns the State before the end of the round.

After the Sender learns the State, the Sender sends a Report to the Receiver. After the Receiver sees the Senders Report, the Receiver decides to Go or Stay resulting in the following payoffs.

Table A.2: Payoffs Given State and Receiver's Decisions

\begin{tabular}{ccc} 
State is & A & B \\
\hline Receiver decides to Go & & \\
Receiver & X & 0 \\
Sender & 13 & 13 \\
Receiver decides to Stay & & \\
Receiver & 10 & 10 \\
Sender & 0 & 0
\end{tabular}


The value of $\mathrm{X}$ depends upon the setting. It will either be $12,18,22$, or 28 .

Notice that only when the State is A are the payoffs higher for all parties when the Receiver decides to Go rather than to Stay. Also notice that the payoff is higher for the Sender if the Receiver decides to Go rather then to Stay in both States A and B. Last, notice that the payoffs do not depend on the Sender's Report, only on the State and whether the Receiver decides to Go or Stay.

What is the Sender's Report? If the Sender learns the State is A, the Sender can decide to report either A or B. If the Sender learns the State is B, the Sender can decide to Report A or B.

\section{Questionnaire 1}

Below, please write down your answers to the following questions. If you have a question please raise your hand and an experimenter will privately answer your question. In a few minutes, an experimenter will review the correct answers.

1. What is the chance the State will be B? $(0,1 / 2,1)$

2. If the Sender knows the State is $B$, what can she report? (A, B, A or B)

3. If the Receiver knew the State was A, would he or she be paid more if they Go rather than Stay? (Yes, No)

4. If the Receiver knew the State was B, would he or she be paid more if they Go rather than Stay? (Yes, No)

5. If the Receiver decides to Go, what will the Sender receive? $(\$ 10, \$ 13)$

\section{Sender's Decision}

We will ask you to make a decision in the role of Sender in four settings. In each setting the payoff to the receiver if he goes in State A is 12, 18, 22, or 28. Specifically, we will ask you to make a decision about what you would report to the paired Receiver in advance of seeing the State drawn. When the experiment starts you will see the following on your screen (see figure $A$ ).

On the left side of the screen you are asked as a Sender to fill in the two entries for each of four settings. If the
State were equal to A, would you report A or B, and if the State were equal to B, would you report A or B? Specifically, for each possible State, you need to tell the computer what Report you will send.

We want you, as the Sender, to say in advance what you would do in both of the scenarios. The computer implements the decisions you make once the State is drawn. Your decision will not affect which State is drawn. Your decision in the role of Sender will not affect the outcome of the settings in which you are a Receiver. Your decision will note effect the other settings.

\section{Receiver's Decision}

We will ask you to make a decision in the role of $\mathrm{Re}$ ceiver in four settings. In each setting the payoff to the receiver in State $\mathrm{A}$ is $12,18,22$, or 28 if he goes. Specifically, we will ask you to make a decision about what you would do for each possible Report the paired Sender might send before you see the Report. When the experiment starts you will see the following on your screen (see figure $A$ ).

On the right side of the screen you are asked as a Receiver to fill in the two entries for each of four settings. If the Senders Report were A, do you want to Go or Stay, and if the Senders Report were B, do you want to Go or Stay? Although, in the end as a Receiver you would see only one Report (A or B), we still want you to tell us what you would do for each possible Report.

Your decision will not affect which Report is sent or which State drawn. Your decision in the role of Receiver will not effect the outcome of the settings in which you are a Sender.

\section{Questionnaire 2}

Below, please write down your answers to the following questions. In a few minutes, an experimenter will review the correct answers.

1. If the Sender elects to report A always, what report will the Receiver see when the State is A? (A, B)

2. If the Sender elects to report A always, what report will the Receiver see when the State is B? (A, B)

3. Does the Receiver always have to Go? (Yes, No) 
Figure A: Input screen used experiment

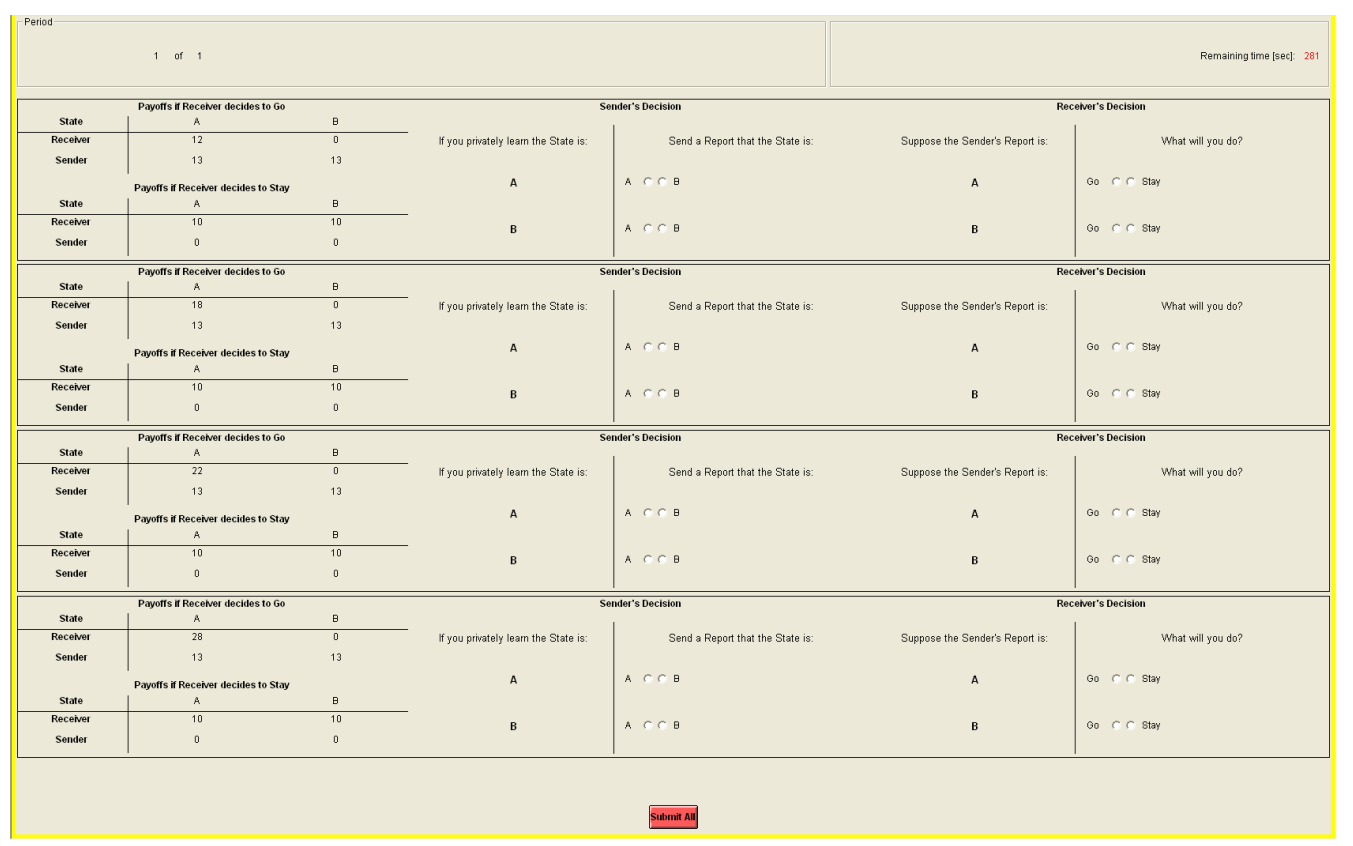

4. If the Sender's Report is B, can the State be A? (Yes, No)

5. If the Sender's Report is A, can the State be B? (Yes, No)

\section{Results of the Round}

After you make both your decisions, the decision in the role of Sender and the decision in the role of Receiver, click on the red Submit button. After all participants input their decisions, the computer will display the outcome screen with the outcome from one of the six settings. One, and only one, of your settings will be randomly selected and you will be paid on the outcome of that setting. For example, if the setting in which you played the role of Receiver was selected for payment, then your screen would show:

How is this table generated? After all the participants have input their decisions, the computer will draw realizations of the State independently for each pair. The computer determines the State randomly as based on Chances of State table. Given the decision input by the Sender, the Report is determined and appears under the caption Senders Report. Note this is the Senders Reportnot the State.

Next, using the decision input by the Receiver, the computer reports if the Receiver decided to Stay or Go for the given Senders Report. This decision is reported in the row titled Receivers decision. Finally, the computer determines the payoffs (taken from Payoffs Given State and Receivers Decisions table) given the State and the decisions for the Sender and the Receiver. These payoffs are reported in the last two rows titled Senders payoff and Receivers payoff.

To summarize, the experiment consists of a single round where:

1. Grouping of Participants: pairs are randomly assigned. 
2. Participant's Decisions: each participant enters both a decision in the role of Sender and a decision in the role of Receiver.

3. Payoffs: the computer randomly selects one setting calculates payoffs using the decisions input.

4. Results for the round: each participant sees payoff from the setting where he/she was the Sender or from the setting where he/she was the Receiver.

At the end of the experiment, you will be paid in private and in cash.

\section{Questionnaire 3}

Below, please write down your answers to the following questions. In a few minutes, an experimenter will review the correct answers

1. You will be paid for one of your settings, not both. (True/False)

2. Suppose the setting where if the Receiver goes in State A he or she gets 18. If the State is A, the Sender reports ' $A$ ' when the State is A, and the Receiver decides to Go when the Report is ' $\mathrm{A}$ ', what is:

a. The Sender's Report? (A, B)

b. The Receiver's payoff? $(0,10,18)$

c. The Sender's payoff? $(0,13)$

3. Suppose the setting where if the Receiver goes in State $\mathrm{A}$ he or she gets 22. If the State is $\mathrm{B}$, the Sender reports ' $A$ ' when the State is B, and Receiver decides to Stay when the Report is ' $A$ ', what is:

a. The Sender's Report? (A, B)

b. The Receiver's payoff? $(0,10,22)$

c. The Sender's payoff? $(0,13)$

The following portion of instructions was distributed after choices were made in aforementioned settings.

\section{Decision Problems}

In this part of the experiment you are asked to make a series of choices in 4 decision problems. How much you receive will depend partly on chance and partly on the choices you make. The decision problems are not designed to test you. What we want to know is what choices you would make in them. The only right answer is what you really would choose.

For each line in the table, please state whether you prefer option A or option B. Notice that there are a total of 4 lines in the table but only one line will be randomly selected for payment. Each line is equally likely to be selected, and you do not know which line will be selected when you make your choices. Hence you should pay attention to the choice you make in every line. After you have completed all your choices the computer will randomly drawn a number from 1 to 4 . The drawn number determines which line is going to be selected for payment.

Your earnings for the selected line depend on which option you chose: If you chose option $\mathrm{A}$ in that line, you will receive $\$ 10$. If you chose option $B$ in that line, you will receive either a positive amount or $\$ 0$. To illustrate, say the line drawn for payment is \#2. To determine your earnings another number is randomly drawn from 1 to 2 . The drawn number is then compared with the numbers in the line selected (see the table). If the drawn number is 1 you earn $\$ 18$, but if the drawn number is 2 you earn $\$ 0$.

While you have all the information in the table, we ask you that you input all your choices into the computer. The actual earnings for this part will be determined at the end, and will be independent of the prior portions.

Table A.4: Option payoffs

\begin{tabular}{|l||c||c|c|}
\hline \multicolumn{1}{|c||}{ Line } & Option $\mathrm{A}$ & \multicolumn{2}{c|}{ Option B } \\
\hline$\# 1$ & $\$ 10$ & $\$ 12$ if 1 is draw & $\$ 0$ if 2 is drawn \\
\hline$\# 2$ & $\$ 10$ & $\$ 18$ if 1 is draw & $\$ 0$ if 2 is drawn \\
\hline$\# 3$ & $\$ 10$ & \$2 if 1 is draw & \$0 if 2 is drawn \\
\hline$\# 4$ & $\$ 10$ & \$28 if 1 is draw & \$0 if 2 is drawn \\
\hline
\end{tabular}




\section{Economic Science Institute Working Papers}

2010

10-18 Deck, C. and Sheremeta, R. Fight or Flight? Defending Against Sequential Attacks in the Game of Siege.

10-17 Deck, C., Lin, S. and Porter, D. Affecting Policy by Manipulating Prediction Markets: Experimental Evidence.

10-16 Deck, C. and Kimbrough, E. Can Markets Save Lives? An Experimental Investigation of a Market for Organ Donations.

10-15 Deck, C., Lee, J. and Reyes, J. Personality and the Consistency of Risk Taking Behavior: Experimental Evidence.

10-14 Deck, C. and Nikiforakis, N. Perfect and Imperfect Real-Time Monitoring in a Minimum-Effort Game.

10-13 Deck, C. and Gu, J. Price Increasing Competition? Experimental Evidence.

10-12 Kovenock, D., Roberson, B.,and Sheremeta, R. The Attack and Defense of Weakest-Link Networks.

10-11 Wilson, B., Jaworski, T., Schurter, K. and Smyth, A. An Experimental Economic History of Whalers' Rules of Capture.

10-10 DeScioli, P. and Wilson, B. Mine and Thine: The Territorial Foundations of Human Property.

10-09 Cason, T., Masters, W. and Sheremeta, R. Entry into Winner-Take-All and Proportional-Prize Contests: An Experimental Study.

10-08 Savikhin, A. and Sheremeta, R. Simultaneous Decision-Making in Competitive and Cooperative Environments.

10-07 Chowdhury, S. and Sheremeta, R. A generalized Tullock contest.

10-06 Chowdhury, S. and Sheremeta, R. The Equivalence of Contests.

10-05 Shields, T. Do Analysts Tell the Truth? Do Shareholders Listen? An Experimental Study of Analysts' Forecasts and Shareholder Reaction.

10-04 Lin, S. and Rassenti, S. Are Under- and Over-reaction the Same Matter? A Price Inertia based Account.

10-03 Lin, S. Gradual Information Diffusion and Asset Price Momentum.

10-02 Gjerstad, S. and Smith, V. Household expenditure cycles and economic cycles, 1920 - 2010. 
10-01 Dickhaut, J., Lin, S., Porter, D. and Smith, V. Durability, Re-trading and Market Performance. 2009

09-11 Hazlett, T., Porter, D., Smith, V. Radio Spectrum and the Disruptive Clarity OF Ronald Coase.

09-10 Sheremeta, R. Expenditures and Information Disclosure in Two-Stage Political Contests.

09-09 Sheremeta, R. and Zhang, J. Can Groups Solve the Problem of Over-Bidding in Contests?

09-08 Sheremeta, R. and Zhang, J. Multi-Level Trust Game with "Insider" Communication.

09-07 Price, C. and Sheremeta, R. Endowment Effects in Contests.

09-06 Cason, T., Savikhin, A. and Sheremeta, R. Cooperation Spillovers in Coordination Games.

09-05 Sheremeta, R. Contest Design: An Experimental Investigation.

09-04 Sheremeta, R. Experimental Comparison of Multi-Stage and One-Stage Contests.

09-03 Smith, A., Skarbek, D., and Wilson, B. Anarchy, Groups, and Conflict: An Experiment on the Emergence of Protective Associations.

09-02 Jaworski, T. and Wilson, B. Go West Young Man: Self-selection and Endogenous Property Rights.

09-01 Gjerstad, S. Housing Market Price Tier Movements in an Expansion and Collapse.

2008

08-10 Dickhaut, J., Houser, D., Aimone, J., Tila, D. and Johnson, C. High Stakes Behavior with Low Payoffs: Inducing Preferences with Holt-Laury Gambles.

08-09 Stecher, J., Shields, T. and Dickhaut, J. Generating Ambiguity in the Laboratory.

08-08 Stecher, J., Lunawat, R., Pronin, K. and Dickhaut, J. Decision Making and Trade without Probabilities.

08-07 Dickhaut, J., Lungu, O., Smith, V., Xin, B. and Rustichini, A. A Neuronal Mechanism of Choice.

08-06 Anctil, R., Dickhaut, J., Johnson, K., and Kanodia, C. Does Information Transparency Decrease Coordination Failure?

08-05 Tila, D. and Porter, D. Group Prediction in Information Markets With and Without Trading Information and Price Manipulation Incentives.

08-04 Caginalp, G., Hao, L., Porter, D. and Smith, V. Asset Market Reactions to News: An Experimental Study. 
08-03 Thomas, C. and Wilson, B. Horizontal Product Differentiation in Auctions and Multilateral Negotiations.

08-02 Oprea, R., Wilson, B. and Zillante, A. War of Attrition: Evidence from a Laboratory Experiment on Market Exit.

08-01 Oprea, R., Porter, D., Hibbert, C., Hanson, R. and Tila, D. Can Manipulators Mislead Prediction Market Observers? 